\title{
DYNAMICS OF AGRARIAN SYSTEMS AND LAND USE CHANGE IN NORTH VIETNAM
}

\author{
Han Quang Hanh ${ }^{1}$, Hossein Azadi ${ }^{2,3,4}$, Thomas Dogot $^{2}$, Vu Dinh Ton ${ }^{1}$, Philippe Lebailly ${ }^{2}$ \\ ${ }^{1}$ Faculty of Animal Science, Vietnam National University of Agriculture, Vietnam \\ ${ }^{2}$ Economics and Rural Development, Gembloux Agro-Bio Tech, University of Liège, Belgium \\ ${ }^{3}$ Centre for Environmental Sciences, Hasselt University, Hasselt, Belgium \\ ${ }^{4}$ Department of Geography, Ghent University, Belgium \\ Received 20 April 2016; Revised 30 August 2016; Accepted 30 August 2016
}

\begin{abstract}
During the period of socio-economic transformation initiated in the late 1980s by the political reform (Doi Moi) in Vietnam, the agrarian systems evolved considerably. In the region around the capital, where the process of industrialization, urbanization, and international integration has been accelerating, a number of questions about the sustainability of those agrarian systems have been raised. By diagnosing and analysing the dynamics of the agricultural systems in Vietnam from 1980 to 2010, this study aims to provide decision-makers with some sectorial and territorial policy options that are able to authorize the sustainable development of agriculture and rural society in the new socio-economic context. By applying a systematic approach, including the historical and adaptive approaches, this study shows how well farmers in the Hai Duong province have adapted to socio-economic and institutional changes, notably by transforming part of their paddy farms into other agricultural land use purposes, such as fish ponds, animal buildings, vegetable fields, and fruit orchards. These rapid changes, however, do not move in a direction that improves the sustainability of agrarian systems. The results revealed that farm holders are now facing many technical and economic contradictions, whereas issues that arise from the land no longer are only related to agricultural purposes. Competition for different functions of land use are now emerging, along with the fragmentation of plots, an imperfect land market, and rising property values are all emerging. The prospect of the sustainability of agricultural systems was also analysed under different scenarios, highlighting the complexity of policy options. Copyright (c) 2016 John Wiley \& Sons, Ltd.
\end{abstract}

KEY WORDS: land use policy; agriculture systems; agricultural land conversion; land fragmentation; agricultural sustainability

\section{INTRODUCTION}

Various definitions of an agrarian system have been introduced by different authors (for example FAO, 1999; Mazoyer \& Roudart, 2006). The agrarian system is a complex open system that is made of two main sub-systems and includes cultivated ecosystems and a productive social system (FAO, 1999; Mazoyer \& Roudart, 2006; Vieira et al., 2015; Xie et al., 2015; Torres et al., 2015) (Figure 1). Agricultural systems around the globe continuously change as a result of enlarging trade blocks, globalization and liberalization, the introduction of novel agro-technologies, changing societal demands, and climate change (Araya et al., 2012; Alexander et al., 2015; Galati et al., 2016; Jlassi et al., 2016). Parallel to the liberalization of global markets, the political ambitions devise those policies which aim to improve the sustainability (specially the soil quality) of agricultural systems in terms of economic viability, environmental soundness, and social acceptability, and to enhance the contribution of agricultural systems to the sustainable

*Correspondence to: Hossein Azadi, Department of Geography, Ghent University, St. Pietersnieuwstraat 33, 9000 Gent, Belgium.

E-mail: hossein.azadi@ugent.be development of society and global ecosystems at macro level (van Ittersum et al., 2008; Smith et al., 2015; Keesstra et al., 2016a). Analyzing the dynamics of farming systems is of great importance in order to comprehend the temporal and spatial transformation of agriculture at different levels. Through long-term development, an agrarian system in a given region can be born, develop, decline, and succeed from one system to another in an evolutionary series (Mazoyer \& Roudart, 2006; Yu et al., 2013). If we do not research and understand the agrarian system, we cannot practice appropriate strategies to improve soil, water, and other natural resources (Mekonnen et al., 2015; Rodrigo-Comino et al., 2016; Hack-ten Broeke et al., 2016; Galati et al., 2016; Novara et al., 2016). This evolutionary series, together with the complexity theory, might be used to inform an adaptive perspective of farm management. In the context of farmlands, these evolutionary theories try to explain how farms generate and adapt to change, and how these processes are intertwined with what happens both at the lower level of individual behaviour and on the higher level of markets as well as in the environment on farms in general. Therefore, the analysis of agrarian systems at any given time and place consists of breaking it down into the two components (i.e. the cultivated 


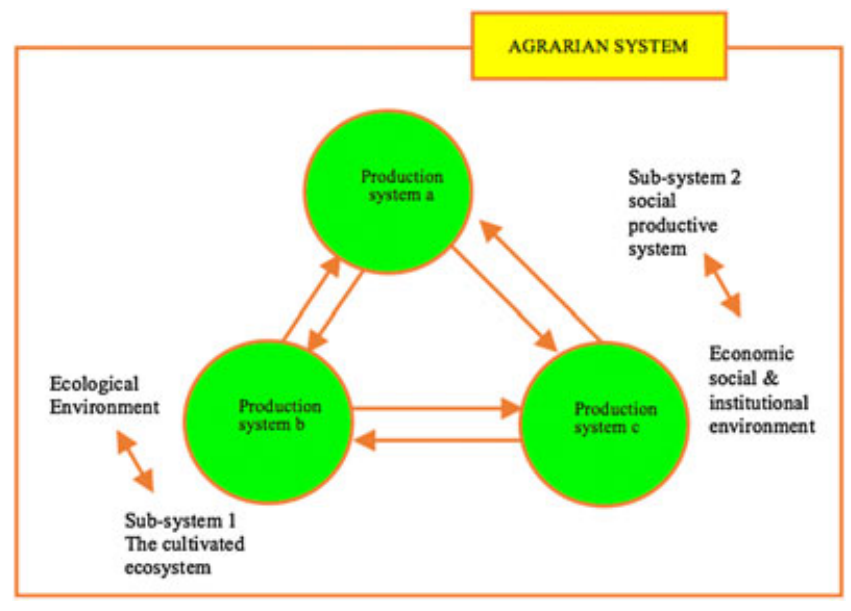

Figure 1. The Agrarian System: a complex open system, made of two subsystems (based on Mazoyer, in Land Reform 1992-1993, FAO) (adapted from FAO, 1999). This figure is available in colour online at wileyonlinelibrary.com/journal//dr

ecosystem and the social productive system) and by studying the organization and the function of each of these subsystems, as well as studying their interrelations (Mazoyer \& Roudart, 2006; Rasmussen et al., 2012).

According to the high complexity of the ecological and socio-economic conditions, there is a wide variety of agricultural systems globally (Hoeks et al., 2014; Rudi et al., 2014). They range from small subsistence farms to large commercial operations and encompass very diverse production patterns. These can include poly-cultures or monocultures, mixed crops and extensive or intensive livestock systems, aquaculture systems, agro-forestry systems, and others in various combinations. Furthermore, the intensity and diversity of these types of agricultural systems have also been changing over time because of the transition that is driven by complex and interacting factors related to production, consumption, trade, and political concerns (Nicholson \& Heleba, 2000; McIntyre et al., 2009; Barati et al., 2015). In their study, Campos et al. (2014) show that wide expanses of native vegetation were converted into croplands on the eastern slope of the Cofre de Perote Volcano (Mexico). Land use changes along this altitudinal gradient correspond to a set of dynamic variables that may affect the microbial activity of the soil. Furthermore, a study by Amuti \& Luo (2014) shows that land use change is mainly a result of intensified human activities, such as land and water exploitation as well as overgrazing. The combined effects of erosive rains, steep slopes, and human land use have caused severe land degradation in the Ethiopian highlands for several thousand years, but since the $1970 \mathrm{~s}$, land rehabilitation programmes have been established in order to reverse such deterioration. Land degradation usually is being seen as a consequence of agricultural growth, urban sprawl, mining, and other human economic activities that have resulted in over-exploiting natural resources (Brevik et al., 2015; Lu et al., 2015; Novara et al., 2015; Keesstra et al., 2016b; Easdale, 2016). Inappropriate agricultural policies, especially in developing countries, have brought about running unsustainable agrarian systems that have resulted in sever land degradation and low quality soils because of overuse of chemical materials, inappropriate agricultural machinery and labour inefficiency. Accordingly, agriculture has often been grown at the cost of land deterioration because of overexploiting of agricultural lands that has resulted in poor soil textures followed by soil erosion in these countries (Novara et al., 2013; Zhang et al., 2015; Costa et al., 2015; Hedo et al., 2015). A study by de Mûelenaere et al. (2014) shows significant LUC in the northern Ethiopian Highlands over the last three decades. Major changes consist of a decrease in bare soil and a considerable increase in bushlands and forests. These changes can be linked to the introduction of land rehabilitation initiatives and prove that land recovery is possible. According to Lasanta et al. (2016), clearing is an appropriate way to reorganize the space in marginal mountain areas without needing excessive investment. Doing so by converts abandoned fields into pasturelands, increasing their area, and consequently increasing livestock feed sources.

Some emerging agriculture systems include organic, urban and peri-urban, and conservation agriculture systems (McIntyre et al., 2009; Beniston et al., 2016). In Vietnam, the popular mixed farming system is called the "VAC" system, which consists of a combination of gardens, ponds, and animal sheds. It is a diverse organization, or combination, of different types of crops (such as rice, roots and tubers, vegetables, trees, and other plants), animals (ruminant and non-ruminants), and aquaculture production (Luu, 2001). This kind of system also changes over time and differs across regions (the delta and the mountain region). Part of that consists of small and traditionally mixed systems, which are primarily based on a home-consumption orientation or self-subsistence. Because of the development of a market-oriented economy, farming households have been gradually expanding their production and the "VAC" system, thereby becoming more commercially oriented. However, numerous traditional systems characterized by low economic efficiency and the use of backward methods still abound, and because of this, farming systems are well known as a dynamic and evolutionary system. A historical approach is usually employed in system analysis because of the perception of changes in environmental situations and because farmers often adapted or adjusted to the new situations by changing their production objectives and exploitation modes. Furthermore, the characteristics and dynamics of an agrarian system are often strongly related to the agro-ecological and socio-economic environments of a given geographic region.

Vietnam has undergone a rapid economic transition over the last few decades, especially since the end of the 1980s. A number of national economic and institutional reforms have been implemented and have led to structural changes in the socio-economic conditions of the country. During the 1980s, the reform policy focused on the reorganization of agricultural production through de-collectivization, 
re-establishment and development of the family smallholding, and market liberalization. These reforms are greatly successful and resulted in a strong growth of agricultural production and a significant alleviation of hunger and poverty.

As reported by many authors, over the last few decades, the agricultural systems in the Red river delta have significantly evolved from subsistence farming to a marketoriented production system under the economic reform or Doi Moi. Two significant contributions to the reform policy were the redistribution of production factors to farmers and the liberalization of the domestic and external market. The economic transition from a central planning economy to a market-oriented one officially approved households as independent economic units and ensured their self-determination when deciding how to develop the agricultural production. During this transition period, the socio-economic and institutional environments of the region have notably changed and now strongly integrate the regional and international market, facilitating and encouraging the development of the intensive and diverse agrarian systems. Muller \& Zeller (2002) investigated the geo-physical, agro-ecological, and socio-economic determinants of past land use changes in Central Highlands of Vietnam and assessed the influence of rural development policies on land cover change. Their results suggest that the first period, from 1975 to 1992 , was characterized by land-intensive agricultural expansion and the conversion of forest into grass and agricultural land. During the second period, since 1992, the introduction of fertilizer, improved access to rural roads and markets, and expansion of the irrigated area enabled a rapid, more labour-, and capital-intensive growth in the agricultural sector. These policies, combined with the introduction of protected forest areas and policies that discouraged shifting cultivation during the second period, reduced the pressure on forests while at the same time increased agricultural productivity and the incomes of a growing population. Forest cover during the second period mainly increased because of the regeneration of areas formerly used for shifting cultivation. The evolution of these systems varies among geographical locations, such as the plain delta, hilly, and mountainous regions as well as between different groups of farmers. However, the above studies have mainly referred to the changes of agrarian systems from the Doi Moi (1980s) to the early 2000s. In fact, during the period between 2000 and 2010, the socio-economic and institutional environments in Vietnam have changed rapidly because of the acceleration of the industrialization and urbanization process and highly international integration. These changes have both positive and negative effects on the evolution trend of farming systems.

The proportion of the agricultural-forestry and fishery households in the Red river delta significantly reduced from $77.26 \%$ in 2001 to $60.48 \%$ in 2006 and to $42.63 \%$ in 2011 . In 2011, the number of agricultural labourers in the delta region declined by 1.16 million workers or by $27.3 \%$ compared with figures in 2006. The area of agricultural land in the delta in 2011 was approximately 780000 ha, which decreased by nearly 36000 ha (or by a $4.3 \%$ reduction) compared with the amount in 2006 (General Statistics Office, 2012). The rural labourers who earned a wage moved to the industrial zones, while the households around the urban areas have become landless farmers. Under these changing conditions, farmers have different strategies of agricultural production in order to better adapt to the new environmental conditions. Therefore, it is greatly important to diagnose agrarian system dynamics during the economic transition and industrialization period (from the Doi Moi up to present) so that policy planners are able to design the appropriate agricultural and rural policies, schemes, and projects for sustainable development in the future.

Because this study focuses on the dynamic or evolution of agrarian systems, it is, therefore, essential to apply the system approach in order to understand all aspects or elements of a system and their relationships in a given socio-economic context at both farm and regional levels (Keith, 1995; Duglas \& Dillon, 1997; FAO, 1999). This approach emphasizes the heterogeneity, complexity, and variability of farmers' production environment that need to be attended to in the analysis as well as in the policy-setting process (Meadows, 2009). In order to understand the heterogeneity and complexity of farm household systems well, the analysis of ecological and socio-economic situations at the farm and regional level is required. However, these situations are always changing across time and vary from one region to another. Thus, understanding its variability and its evolutionary process is necessary in order to explain the heterogeneity, complexity, and variability of farmers' production systems.

By applying the system approach, this study, first, classifies farmers and farming systems into alternative categories based on several appropriate criteria. The study then focuses on the analysis of system elements at the farm level (the livestock production systems, the cropping systems, and the non-farm activities) and the interaction among them. Farmers' production environments (natural resources, production means, household characteristics, farmer's objectives or interests, etc.) were considered in the analysis in order to explain the differentiation of performance and economic efficiency between farming system categories. Moreover, the analysis will broaden to an agrarian system at the regional level by taking into account the diversity and variability of the ecological and socio-economic contexts in order to better understand the complexity of different agrarian system typologies.

\section{MATERIAL AND METHODS}

\section{Study Area}

The study was conducted in the Hai Duong province, a central region in the Red river delta, North Vietnam (Figure 2). The total natural area of the province is $1651.85 \mathrm{~km}^{2}$, which is $7.8 \%$ of the total area of the Red river delta and $0.5 \%$ of the whole nation. The province is slightly sloped from the 


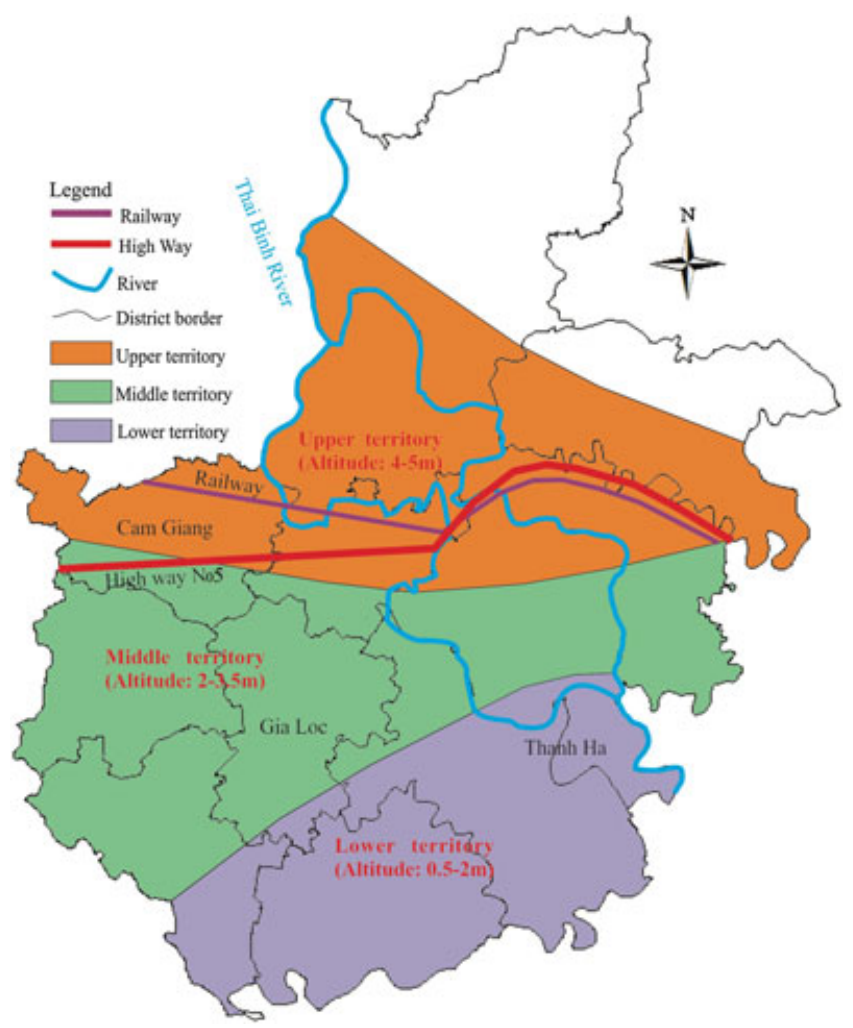

Figure 2. The sketch map of the Hai Duong province (source: Secondary data and participatory works, 2010). This figure is available in colour online at wileyonlinelibrary.com/journal/ldr

northwest to the southeast because of the difference in altitude. The plain delta (from 0.9 to $5 \mathrm{~m}$ in altitude) shares $1389.00 \mathrm{~km}^{2}$, equal to $84.09 \%$ of total natural areas, and is shaped and is made up of deposits of layers of alluvium soil from the Thai Binh river system, which is advantageous for diversified agricultural productions.

Hai Duong is in the process of accelerated industrialization and urbanization that strongly influence the agricultural land areas and rural labour structure. The area of industrial land increased from 647.75 ha (6 large industrial zones) in 2005 to 2090 ha (10 concentrated industrial centres) in 2010. According to the province's development plan, by 2015 and 2020, the total area of industrial land will increase up to 3800 ha in 18 industrial parks.

During the industrialization, there has been a gradual reduction of agriculture-forestry-fishery land and an increase in the non-agricultural land area. The proportion of these two items of land in 2002 was $69.2 \%$ and $30 \cdot 1 \%$, respectively. In 2009, agriculture-forestry-fishery land only made up $64.4 \%$, whereas the non-agricultural land accounted for $35.1 \%$ of the land. There was a significant decline in the paddy farms $(8.8000$ ha or $11.3 \%)$ from 2002 to 2007, mostly because land was converted into industrial zones and urban areas. Furthermore, low paddy farms were converted into fish ponds and perennial crops, resulting in an increase of these land areas $(23.8 \%$ and $43.8 \%$ respectively).

Furthermore, because of the rapid development of the industrialization and urbanization process, the structure of the population has changed between 1997 and 2008, with a slight decrease in rural residents (from $88.8 \%$ in 1997 to $81.8 \%$ in 2008) and a corresponding increase in urban inhabitants (from $11.2 \%$ in 1997 to $18.2 \%$ in 2008). Large areas of fertile land were withdrawn from farm households in order to install industrial companies and buildings, causing some groups of farmers to become landless and jobless. Approximately, per one hectare of agricultural land converted into an industrial zone, about 10 agricultural labourers lost their jobs. A survey conducted among 819 households in the Ai Quoc commune (Nam Sach district) in 2008 showed that agriculture-based families declined from $59.9 \%$ in 2003 , to $40.1 \%$ in 2007 , while the number of free labourers who did not have a stable job increased from $13 \cdot 1 \%$ to $23 \cdot 1 \%$ during this period.

The economic structure has changed remarkably into a higher contributor of industry, construction, and service sectors (increased from 36.6\% and 28\% in 1997 to $43.8 \%$ and $30.5 \%$ in 2008 , respectively) and now contributes a lower share of agricultural production (reduced from $35.4 \%$ in 1997 to $25.7 \%$ in 2008). Significant changes have occurred since the year 2000, when the process of industrialization and urbanization expanded. A wide variety of industrial factories were built and enlarged in large zones, engaging a number of agricultural labourers, as well as agricultural land areas. Among all of these factories, service activities were therefore encouraged in order to more rapidly develop through the development of industrial zones and urban areas.

\section{Data Collection and Analysis}

The study employed both qualitative and quantitative data collected from primary and secondary sources. Secondary data were collected from different official sources, including annual statistic books published by the General Statistics Office (GSO), the Hai Duong Statistics Office (HSO), maps, historical books, annual reports, and summaries of local authorities in villages, communes, districts, and province departments. Furthermore, several books and documents such as dissertations, project reports, etc. were used as complementary sources for this study. Primary data were also obtained from participatory works and household surveys through a semi-structured questionnaire. This research was a qualitative research based on several case studies to examine different cropping and livestock production systems of a small number of selected holdings. The Hai Duong province was divided into three agro-ecological and socio-economic zones by stratification method (map-based analysis and transect walks). The zones include the upper (4 to 5-m altitude, animal-aquaculture production), middle (2 to 3.5-m altitude, vegetable cultivation), and the lower zone $(0.5$ to $2-\mathrm{m}$ altitude, perennial fruit cultivation). In each zone, two representative communes belonging to one district were chosen for the household survey. At the regional level, secondary data analysis and exploratory discussions with local witnesses (the chief of the commune, head of agricultural cooperative, veterinarian staff, etc.) were conducted in order to identify the evolution of the agricultural systems over the last 
decades. Sampling of communes is not necessarily representative of the entire range of holding types of the study region.

The classification and production system typology of farming households were also implemented during these participatory works through a qualitative method rather than statistical techniques. Farming households in each region were classified into different categories according to their agricultural production activities (or production systems). Then, households belong to different production systems were randomly selected for the surveys. The purpose of the household sampling was to understand the diversity and the mechanism of the dynamics of the production systems in the study site. It was a qualitative research based on the case studies in order to examine, in detail, the different cropping and livestock production systems of a small number of pre-selected holdings. The most important issue in the household sampling was to understand, very precisely and for each production unit in the sample, what class of holding it presents. Therefore, the number of households chosen for in-depth surveys may vary from one type of farmers or production system to another, strongly depending on the diversity of each production system and the accessibility of each region. As shown in Table I, in total, 94 households in six communes (three districts) were interviewed in order to identify the evolution of agricultural systems from 1980s to 2000s, using a retrospective method.

\section{RESULTS AND DISCUSSION}

\section{Characteristics of the Traditional Rice-Based Agrarian Systems}

In the 1980s, the socio-economic crisis had a great impact on agricultural production and rural society. Food security was one of the biggest challenges that numerous households faced and became the most important government strategy and priority. Therefore, at that time, the rice production system was seen as the basic mode of the environmental exploitation of farmers. Rice was the main crop and was cultivated by two crops per year, namely the spring and summer rice crops. Furthermore, other crops and livestock species were also integrated into the production system known as the VAC system (a combination of crop cultivation, livestock production and aquaculture production). The traditional rice-based agrarian system was characterized by small-scale and a low intensive level of production (Figure 3).

According to the results of the participatory discussions and secondary data, a traditional rice-based agrarian system is characterized by the predomination of rice cultivation in combination with winter crops, animal production, and fish ponds. Rice, which is cultivated in spring and summer, is of great importance and was significantly developed in planted areas in order to ensure food security. Several winter crops, especially sweet potatoes, potatoes, and maize, were expanded in order to meet the food requirements of most farm households. The diverse herds of animals that were kept, however, were small scale in relation to the crop production.

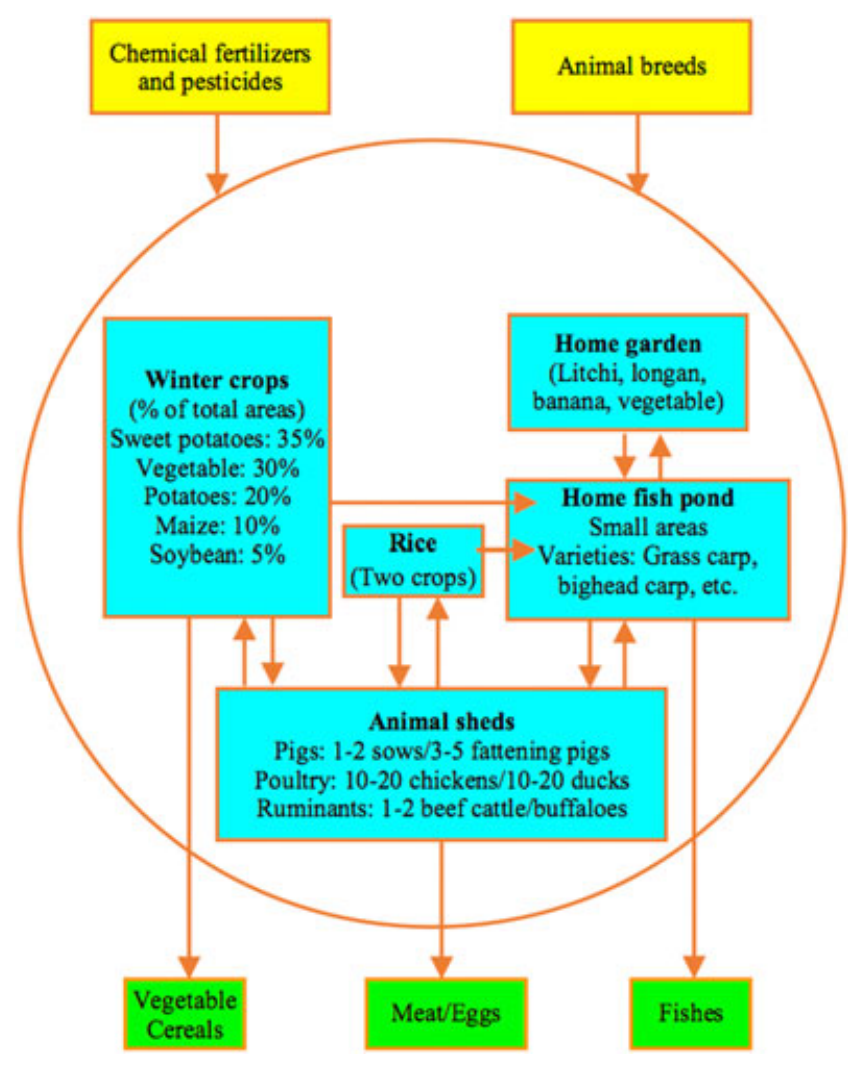

Figure 3. Flow diagram of the traditional rice-based agrarian system in Hai Duong in 1980s (Source: Participatory discussions and secondary data). This figure is available in colour online at wileyonlinelibrary.com/journal/ldr

Table I. Distribution of the surveyed households according to different types of production systems

\begin{tabular}{ll}
\hline Agrarian systems & \multicolumn{1}{c}{ Production systems } \\
\hline Animal-Aquaculture based system & Specialized livestock-fish production system \\
& Diversified livestock -fish-crop production system \\
Annual vegetable cropping based system & Specialized cabbage-melon cropping system \\
& Diversified vegetable cropping system \\
Perennial fruit cropping base system & Specialized guava cropping system \\
& Diversified litchi-pig production system \\
Total & Diversified litchi-kumquat-guava cropping system \\
\hline
\end{tabular}


Spatial Dynamics of the Agrarian Landscape: Chronological Diagrams of Local Transects

As mentioned before, the Hai Duong province was divided into three main agro-ecological and socio-economic zones according to their physical environments, socio-economic conditions, and agricultural features. These encompass the upper, middle, and lower regions. The evolution of the agrarian landscape was tracked during the last three decades through transect walks based on participatory discussions with local residents and personal observations (Figure 4).

In general, from the 1980s, the farming systems in the different zones were gradually transformed from traditional rice-based production systems into a more diversified model during the 1990s and then into a specialized and diversified system during the 2000s. However, under the given changing conditions of the environmental contexts of each region, this evolution had specific characteristics and resulted in different agricultural systems among geographical zones at the current time.

Over the last three decades, the changes within the agrarian landscape in the upper zone are the result of the gradual replacement of paddy farms with fish ponds and animal buildings in remote areas and with industrial parks in the town centre. It was observed that through the 1990s and 2000 s and as a result of the paddy farm conversion programme, fish ponds and animal buildings have moved from homestead land to the paddy farms. During the 2000s, large areas of agricultural lands, especially paddy farms, were converted to industrial zones or urban areas.
Unlike the upper zone, since 1990s, the change of agrarian landscape in the middle zone was viewed as the enlargement of several vegetable crops. The great advantages of large plane fields, fertile soil, and favourable irrigation systems strongly encouraged growers to expand their vegetable crops. However, during the 2000s, a certain area of land that was previously used for rice and vegetable crops was instead used for the installation of a number of industrial companies.

In the lower zone of Hai Duong, the significant change of the agrarian landscape was caused by paddy farms being converted into litchi gardens in 1990s and was then diversified into fruit plantations in the 2000s. In the past, litchi was mostly grown in home gardens, while in the 1990s, litchi trees gradually replaced rice. Then, in the 2000s, certain litchi plantations in this zone were cut down and converted into other fruit crops, such as guava, kumquat, etc. During these decades, the annual crop-based land area was changed into perennial fruit-based gardens.

\section{Dynamics of the Animal-Aquaculture Based Agrarian System in the Upper Zone in the 1990s and 2000s}

During the last two decades, the agrarian system in the upper zone of Hai Duong has evolved from a traditional rice-based system into a diverse animal-aquaculture-crop production system and into a specialized animalaquaculture based system in the 1990s and 2000s, respectively. This process was mainly because of the conversion of paddy farms into fish ponds and animal

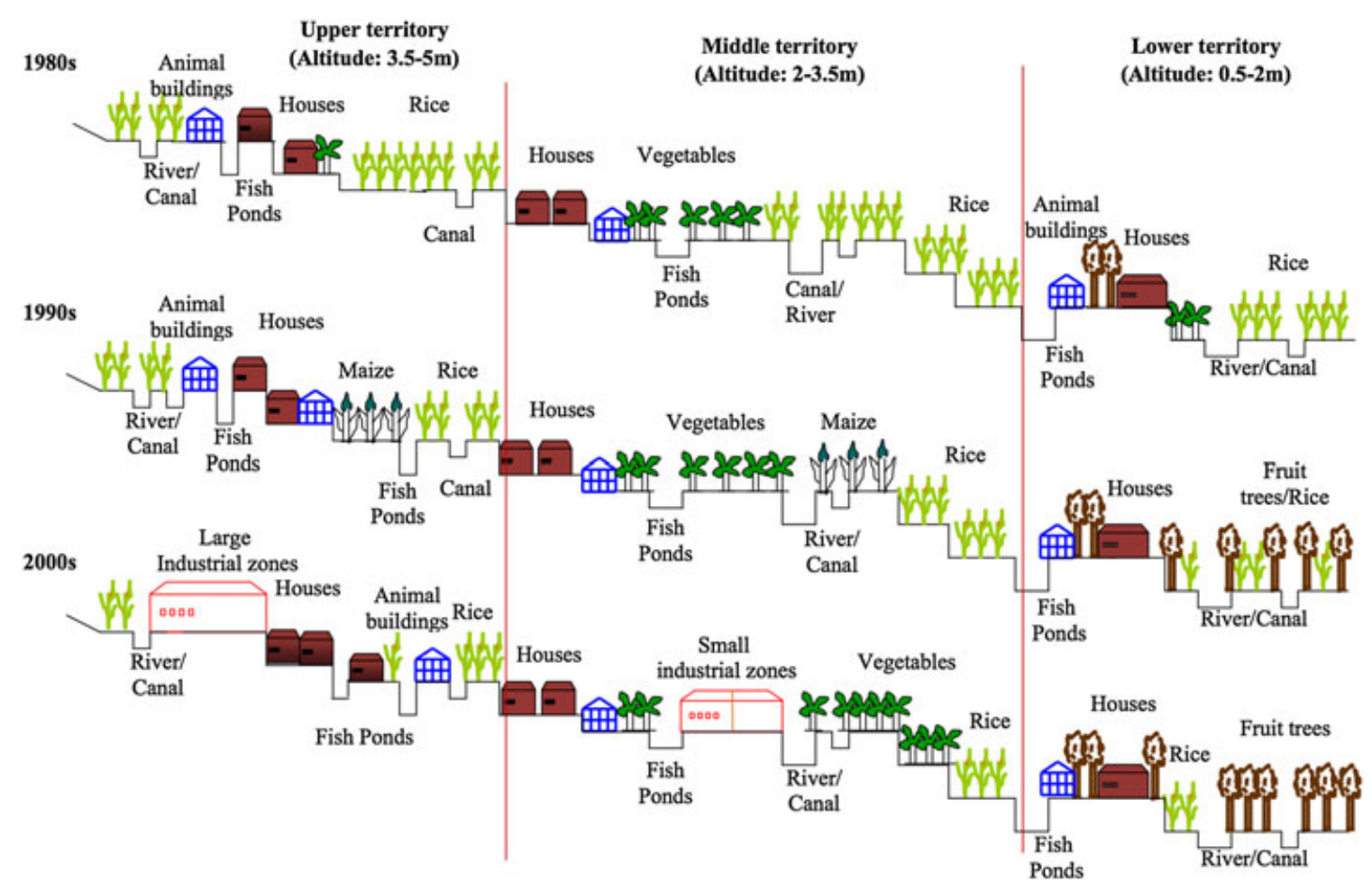

Figure 4. Chronological diagram of the local transect of the Hai Duong province (Source: Participatory discussions and personal observations, 2010). This figure is available in colour online at wileyonlinelibrary.com/journal/ldr 
buildings. In the 1990s, some of the lowland areas in paddy farms were, first, turned into fish ponds and animal buildings, and since then, animal and fish production has developed rapidly. At that time, winter crops, especially maize and soybean, were widely planted in order to provide feed for animals and fish. The integrated animal-fish-crop production system was the dominant model in this zone. In the 2000s, expanding of farm size and the increased intensity of input use enhanced the specialization of production systems. Farm holdings then specialized in large-scale pig or poultry production and applied fish mono-culturing. The following section introduces this dynamic of animal-aquaculture based agrarian systems in the upper zone in more detail.

\section{Changes of Agricultural Land Areas of Surveyed Households}

The paddy farms of most farming households have expanded slightly over the last two decades. During this period, almost all smallholders kept a certain area of paddy farms in order to maintain food autonomy for their family. Some, who were too old or had migrated to other regions, sold or divided the land to others. Thus, the land area of paddy farms that belonged to individual households in the two production systems in 2010 was about $1 \cdot 2-1 \cdot 3$ times higher than those in 1993 (Table II).

On the other hand, the changes in the amount of land devoted to fish ponds among most households have been dramatic through the years (Table II). In 1993, the number of households who had small areas for fish ponds was very limited. Many of them then purchased or rented more surrounding water surfaces from neighbours or from common water borders of the commune in order to culture

Table II. Changes of paddy farms and fish pond areas of surveyed households

\begin{tabular}{|c|c|c|c|c|}
\hline \multirow[t]{2}{*}{ Land items } & \multicolumn{2}{|c|}{$\begin{array}{l}\text { Livestock-fish } \\
\text { system }(n=13)\end{array}$} & \multicolumn{2}{|c|}{$\begin{array}{l}\text { Livestock-fish- } \\
\text { crop system } \\
\quad(n=25)\end{array}$} \\
\hline & $\begin{array}{l}\text { Areas } \\
\left(\mathrm{m}^{2}\right)\end{array}$ & $\begin{array}{c}\% \\
\mathrm{HHs}\end{array}$ & $\begin{array}{c}\text { Areas } \\
\left(\mathrm{m}^{2}\right)\end{array}$ & $\begin{array}{c}\% \\
\mathrm{HHs}\end{array}$ \\
\hline \multicolumn{5}{|l|}{ Paddy farms } \\
\hline Paddy farms 1993 & $1384 \cdot 6$ & 100 & $1827 \cdot 4$ & 100 \\
\hline Rent land & $27 \cdot 7$ & $38 \cdot 5$ & $79 \cdot 2$ & $12 \cdot 5$ \\
\hline Purchased land & $180 \cdot 0$ & $38 \cdot 5$ & $292 \cdot 3$ & $25 \cdot 0$ \\
\hline Inherited land & $166 \cdot 2$ & $15 \cdot 4$ & $201 \cdot 6$ & $12 \cdot 5$ \\
\hline Sold land & 0 & 0 & $273 \cdot 6$ & $24 \cdot 0$ \\
\hline Paddy farms 2010 & $1758 \cdot 5$ & 100 & $2126 \cdot 9$ & 100 \\
\hline $\begin{array}{l}\text { Difference (2010/ } \\
1993)\end{array}$ & $373 \cdot 8$ & 0 & $299 \cdot 5$ & 0 \\
\hline Fish pond areas & & & & \\
\hline Fish pond 1993 & $450 \cdot 0$ & $30 \cdot 8$ & $440 \cdot 0$ & $16 \cdot 0$ \\
\hline Rent area & $2232 \cdot 0$ & $53 \cdot 8$ & $1502 \cdot 0$ & $36 \cdot 0$ \\
\hline Purchased area & $1440 \cdot 0$ & $38 \cdot 5$ & $944 \cdot 0$ & $24 \cdot 0$ \\
\hline Fish pond 2010 & $4122 \cdot 0$ & $76 \cdot 9$ & $2886 \cdot 0$ & $72 \cdot 0$ \\
\hline $\begin{array}{l}\text { Difference (2010/ } \\
1993)\end{array}$ & $3672 \cdot 0$ & $46 \cdot 1$ & $2446 \cdot 0$ & $56 \cdot 0$ \\
\hline
\end{tabular}

(Source: Surveyed data in 2010-2011). fish. They often rented the common pools of the commune for a long-term use (for example about 20 years in the Tan Truong commune) at very low prices (for example $70 \mathrm{~kg}$ rice sao ${ }^{-1}$ year $^{-1}$ for water surfaces and $30 \mathrm{~kg}$ rice $\mathrm{sao}^{-1}$ year $^{-1}$ for the area of pond borders in Tan Truong). Therefore, the difference in the area of fish pond between 2010 and 1993 is very high, being about 9.2 times more in the livestock-fish systems and 6.6 times more in the livestockfish-crop systems in 2010, when compared to 1993.

\section{The Variation of Livestock Herd Size of the Surveyed Households}

During the first period (1993-2003), the diversified livestock production system was widely employed by most farms. This production system was characterized by a diverse combination of species of livestock at a medium-scale production.

However, the difference between the two production systems was more significant in the second stage (2003-2010) than that in the previous period (Table III). During these years, the households that employed the livestock-fish production system expanded their production scale by increasing the number of animals that they reared. Most farmers specialized in pig or poultry production, which had a high density of animal population. Conversely, smallholders in the livestock-fish-crop production system sustained a diversified production mode by keeping the flock size of the different animal species small.

Over the first period (1993-2003), there was a little difference in the population of sows between households using the two various livestock production systems and at that time, a high percentage of farms practised small scale of pig production (about one to three sows and 10-30 growing pigs). Then, in 2010, a number of farmers using the livestock-fish production system increased their animal herd size (50\% of them kept more than nine sows and more than 90 growing pigs), while others still maintained a small or medium livestock flock size $\mathbf{( 7 6 . 9 \%}$ households in the livestock-fish-crop production system had one to three sows and $91.7 \%$ of them raised 10-30 fattening pigs). Thus, over this period, the difference in the pig herd size among the households applying two different livestock production systems was more significant than before this time period.

\section{Dynamics of the Vegetable-Based Agrarian System in the Middle Zone in the 1990s and 2000s}

Vegetable crops are widely cultivated in the middle region of the Hai Duong province, which hosts many advantageous conditions for this kind of crop. The province is known as one of the largest vegetable supplying centres in the Red river delta. A highly diverse variety of vegetable crops are planted here, such as cabbage, kohlrabi, cauliflower, bean, etc. A huge amount of these kinds of vegetables are transported to both local and regional markets every year, not only in the North but also to the South of Vietnam. Over the last two decades, the vegetable-based cropping system has significantly evolved, as shown in Figure 5. 
Table III. Variation of livestock flocks of surveyed households

\begin{tabular}{lrrrrrrr}
\hline $\begin{array}{l}\text { Livestock flocks } \\
\text { (head/cycle) }\end{array}$ & \multicolumn{3}{c}{ Livestock-fish system $(n=13)$} & & \multicolumn{3}{c}{ Livestock-fish-crop system $(n=25)$} \\
\cline { 2 - 3 } & 1993 & 2003 & 2010 & & 1993 & 2003 & 2010 \\
\hline Sows & $1 \cdot 2$ & $3 \cdot 0$ & $12 \cdot 3$ & & $1 \cdot 7$ & $3 \cdot 9$ & $2 \cdot 8$ \\
Growing pigs & $9 \cdot 8$ & $23 \cdot 8$ & $88 \cdot 3$ & & $7 \cdot 2$ & $32 \cdot 1$ & $20 \cdot 7$ \\
Chickens & $344 \cdot 0$ & $1216 \cdot 7$ & $2583 \cdot 3$ & & $65 \cdot 0$ & $153 \cdot 1$ & $262 \cdot 5$ \\
Ducks & $350 \cdot 0$ & $335 \cdot 0$ & $1000 \cdot 0$ & & $20 \cdot 0$ & $345 \cdot 0$ & $190 \cdot 6$ \\
\hline
\end{tabular}

(Source: Household surveys, 2010-2011).

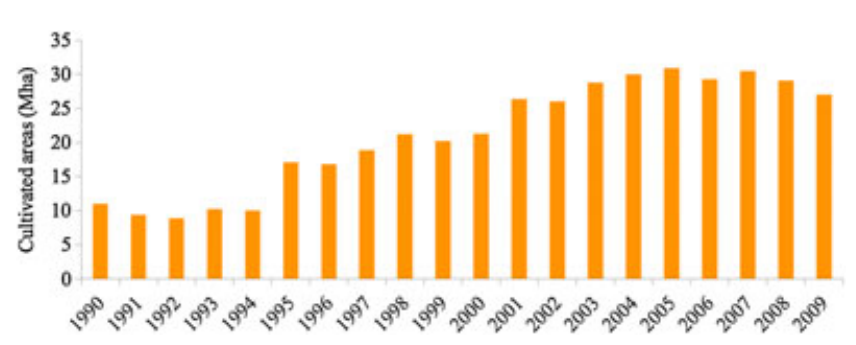

Figure 5. Evolution of vegetable cultivated areas in Hai Duong province (Source: Hai Duong statistics Office, 1995, 1998, 2001, 2006, 2010). This figure is available in colour online at wileyonlinelibrary.com/journal/ldr

\section{The Expansion of Vegetable Crop Areas at the Provincial Level}

As one of the main cash crops of the province, the cultivation of vegetables has been notably promoted in Hai Duong in recent years. The cultivated area of vegetable crops varied dramatically across the different geographical locations of this zone, as well as across the years, according to the changes in environmental contexts and market demands. In general, the planted areas of almost all vegetable crops greatly increased during the study decades (1990s and 2000s) (Figure 4).

The expansion of vegetable crops started between 1993 and 1995, when paddy farms were redistributed to households for long-term use. At that time, vegetables were mostly grown during the winter season, with limited areas where soybean and maize was mostly planted as the major source of animal feed. Then, during the period of 2000-2010, the cultivated surfaces of vegetables increased rapidly when vegetable crops were grown largely in response to their increasing demand among consumers in urban areas. Total area of vegetable cultivation expanded from $21 \cdot 3$ thousand ha in 2000 to 30.5 thousand ha in 2007 , with a diverse range of species, such as cucumber, cabbage, cauliflower, etc. The extension into the markets in the central and southern regions of the country provided to be a great opportunity in order to enhance the production of vegetable crops. Thus, in some districts, a number of large specialized vegetable fields were developed in order to provide a huge and stable amount of vegetables to the surrounding regions and southern markets.

\section{The Increase of the Rotation Cycle of Vegetable Crops}

Over the last two decades, crop rotation has considerably changed from rice-based crop cultivation, to a vegetablebased culture (Figure 6). In the 1980s, like many other

\begin{tabular}{|c|c|c|c|c|c|c|c|c|c|c|c|c|}
\hline \multirow{2}{*}{ Period } & \multicolumn{12}{|c|}{ Months } \\
\hline & 1 & 2 & 3 & 4 & 5 & 6 & 7 & 8 & 9 & 10 & 11 & 12 \\
\hline $1980 \mathrm{~s}$ & \multicolumn{5}{|c|}{ Spring rice } & \multicolumn{5}{|c|}{ Summer rice } & \multicolumn{2}{|c|}{ Winter crop } \\
\hline $1990 \mathrm{~s}$ & \multicolumn{5}{|c|}{ Spring rice } & \multicolumn{4}{|c|}{ Soybean } & \multicolumn{3}{|c|}{ Vegetable'maize } \\
\hline $2000 \mathrm{~s}$ & \multicolumn{5}{|c|}{ Spring rice } & \multicolumn{2}{|c|}{ Meloa } & \multicolumn{3}{|c|}{ Early Cabbage } & \multicolumn{2}{|c|}{ Main Cabbage } \\
\hline
\end{tabular}

Figure 6. Changes of the crop calendar in Gia Xuyen commune (Source: Participatory appraisals with chief of Agricultural Cooperative of Gia Xuyen commune, 2010). This figure is available in colour online at wileyonlinelibrary.com/journal/ldr

regions of the province, two rice crops were cultivated during the spring and summer. In winter, a sub-crop was gradually developed within a very limited land area, which had a number of advantages for the vegetable cultivation, such as fertile soil, water supply availability, etc. During the 1990s, crop rotation changed from summer rice to soybean cultivation, which changed because of the increasing demand for animal feed during this time. As winter crops were being cultivated, farmers started to grow early vegetable crops, because, in October, they would be able to sell their products, the main crops, at a higher price than normal. Then, in the last part of the 2000s, when the demand for vegetables in the local market rapidly increased, most of the farming households only grew one rice crop per year. Instead, they invested more in vegetable cultivation by developing different varieties of crops each harvest.

\section{Changes of Farm Size at the Farm Level}

It has been observed that those that grow vegetables in both cropping systems have dramatically expanded the area cultivated land since 1993 up to now. In 2010, the total vegetable land area of the households studied was nearly double when compared with those in 1993. This increase was not because of the growth of the family size, but rather, the significant increase of land area per capita (Table IV).

These increased areas mostly came from rented land, as agricultural land is an important property of the farmers, most of them kept their land and rented it out if they could not continue farming. These informal renting contracts varied vastly among farming households. Normally, they discussed and drew up a short-term informal verbal agreement to rent the land for 3 or 5 years. They might also rent land annually just to cultivate winter crop vegetables and had to give the land plots back to the owners for the next rice crop. Thus, the renting price varied from, not only the lease 
Table IV. Changes of vegetable cultivated land areas of surveyed households

\begin{tabular}{|c|c|c|c|c|c|}
\hline \multirow[t]{2}{*}{ Periods } & \multirow[t]{2}{*}{ Vegetable cultivated areas } & \multicolumn{2}{|c|}{ Cabbage-melon system $(n=13)$} & \multicolumn{2}{|c|}{ Diversified vegetable system $(n=17)$} \\
\hline & & Mean & $\mathrm{SD}$ & Mean & SD \\
\hline \multirow[t]{2}{*}{ 1993-1995 } & Total areas $\left(\mathrm{m}^{2}\right.$ household $\left.{ }^{-1}\right)$ & $1035 \cdot 5$ & $592 \cdot 0$ & $1163 \cdot 1$ & $512 \cdot 4$ \\
\hline & Areas per capita $\left(\mathrm{m}^{2}\right.$ person $\left.^{-1}\right)$ & 384 & - & 360 & - \\
\hline \multirow{3}{*}{$\begin{array}{l}\text { Transforming period } \\
2010\end{array}$} & Expanded areas $\left(\mathrm{m}^{2}\right.$ household $\left.{ }^{-1}\right)$ & 931.8 & $726 \cdot 3$ & $960 \cdot 9$ & $375 \cdot 7$ \\
\hline & Total areas $\left(\mathrm{m}^{2}\right.$ household $\left.{ }^{-1}\right)$ & $1967 \cdot 3$ & $878 \cdot 4$ & $2124 \cdot 0$ & $475 \cdot 8$ \\
\hline & Areas per capita $\left(\mathrm{m}^{2}\right.$ person $\left.{ }^{-1}\right)$ & $565 \cdot 2$ & $303 \cdot 1$ & $490 \cdot 6$ & $98 \cdot 9$ \\
\hline
\end{tabular}

(Source: Household surveys, 2010-2011).

period, but also the location of the land parcels. For instance, the average price to rent land in 2010 in the Gia Xuyen commune was $100 \mathrm{~kg}$ rice per sao $\left(360 \mathrm{~m}^{2}\right)$ per year. The return of this rice might be received directly or indirectly by converting it into cash at its present market value.

These types of renting contracts are very flexible and are useful to both land owners and the tenants. The land owners, who were engaged in other production activities or were unable to work on the farm, are able to keep their land while receiving a stable return. On the other hand, land tenants with limited agricultural land area able to have access to land and to increase their production scale.

\section{Dynamics of the fruit-based agrarian system in the lower zone in the 1990s and 2000s}

The change of rice and fruit cultivation at the farm level

The sudden decline of rice cultivation. A significant change occurred in 1993 when most of the households in the Thanh Son commune implemented a complete land conversion, from rice into litchi. At that time, $100 \%$ of the rice land areas were converted to litchi orchards. Since then, all households in the litchi-livestock system and the litchi-kumquat-guava system in Thanh Son do not have a paddy rice supply. Thus, they had to buy rice every year for daily consumption. In the Lien Mac commune, where the guava cropping system was dominant, a certain area of rice crops was sustained in order to support food self-sufficiency, though it was very limited. Therefore, each household only owned a small plot of rice, measuring, on average, about $459 \mathrm{~m}^{2}$ per household. Furthermore, not all farming households had paddy farms as only $62.5 \%$ of the total surveyed households of the guava system had access to these small plots of land. According to the results, $37.5 \%$ of total households had to rent more land from surrounding areas in order to cultivate rice. Obviously, keeping a stable area for rice is crucial in order to maintain the food security of farming households, especially in case of the increasing price of rice in the market.

\section{The Development of Perennial Fruit Plantations}

Over the last few years, there has been a rapid expansion of fruit orchards in the study sites. Once the Land Law, which provides farmers with all basic rights over their land, was issued in 1993, most farmers converted the entirety of their paddy farms into litchi plantations between 1993 and
1995. Since then, a majority of producers followed this strategy in order to access more land surfaces and to develop fruit cultivation. As a result, their farm size in 2010 was 1.5 to 2 times higher than that in 1993 (Table V).

In the litchi-livestock production system, most of the households still kept their litchi gardens because they invested more in livestock production. However, in the two other cropping systems, litchi trees have been partly cut down and changed into guava and kumquat plantations.

The increase of fruit lands was mainly the result of the land purchasing process of households. The high profitability of litchi in the 1990s also made it more affordable for litchi growers to buy plots of land from other households, not only in Thanh Ha, but also in other districts of the Hai Duong province and in mountainous regions such as Quang Ninh, Bac Giang, Thai Nguyen, etc, which were located far away from their respective properties. Because of the long-term investment in perennial fruit orchards, farmers preferred to purchase land in order to then rent it. The percentage of the purchased lands was (between $60 \%$ and $89 \%$ ) more than the rented or inherited lands (Figure 7). The excessive development of litchi was also the main reason for the following decline in its price.

The rapid and unplanned development of litchi gardens caused a significant reduction in its price and changed its cropping pattern. The average fresh litchi price in the Thanh

Table V. Evolution of rice and fruit land areas of surveyed households $\left(\mathrm{m}^{2}\right.$ household $\left.{ }^{-1}\right)$

\begin{tabular}{llccc}
\hline Period & $\begin{array}{c}\text { Cultivated } \\
\text { crops }\end{array}$ & $\begin{array}{c}\text { Guava } \\
\text { system } \\
(n=8)\end{array}$ & $\begin{array}{c}\text { Litchi- } \\
\text { livestock } \\
\text { system } \\
(n=8)\end{array}$ & $\begin{array}{c}\text { Litchi- } \\
\text { Kumquat- } \\
\text { Guava } \\
\text { system } \\
(n=10)\end{array}$ \\
\hline 1993 & Rice & 2227.5 & 1980 & 1836 \\
2010 & Rice & 495 & 0 & 0 \\
& Litchi & 225 & 3750 & 1314 \\
& Guava & 2691 & 210 & 630 \\
& Kumquat & 0 & 0 & 1746 \\
$\begin{array}{l}\text { Total } \\
\text { difference }\end{array}$ & Total & 3411 & 3960 & 3690 \\
$\begin{array}{l}\text { Difference } \\
\text { based on }\end{array}$ & Purchased & $1183 \cdot 5$ & 1980 & 1854 \\
land tenure & Inherit & $923 \cdot 5$ & 1950 & 1800 \\
system & Rent & 270 & 30 & 54 \\
\hline
\end{tabular}

(Source: Household surveys, 2010-2011). 


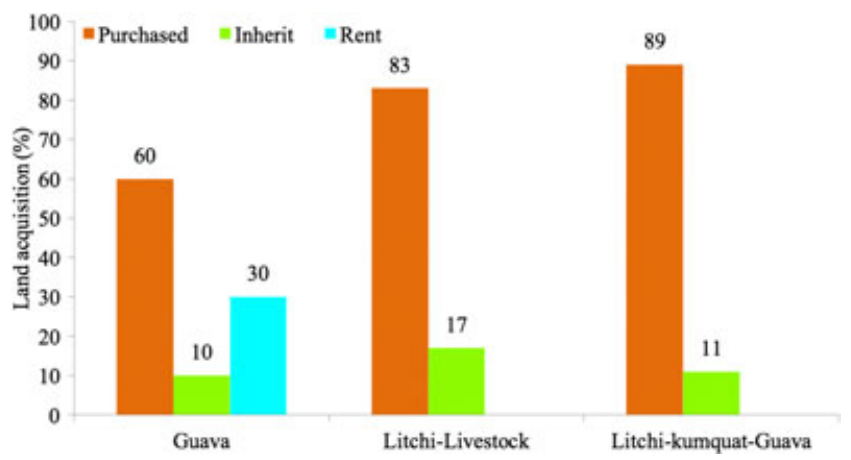

Figure 7. The frequency distribution of land acquisition in each study area (Source: Household surveys, 2010-2011). This figure is available in colour online at wileyonlinelibrary.com/journal/ldr

Ha market decreased from $15000 \mathrm{VND} \mathrm{kg}^{-1}$ in 1995 to $3500 \mathrm{VND} \mathrm{kg}^{-1}$ in 2003 , followed by $2500 \mathrm{VND} \mathrm{kg}^{-1}$ in the following year. Thus, litchi growers tended to fail in their endeavours, despite achieving a high level of productivity and increased yields. To adapt to this downward trend, many producers diversified their perennial fruit tree orchards. Guava, kumquat, banana, and other species were grown as a substitute for litchi in some gardens in the Thanh Ha district. On some paddy farms, where litchi was planted by heaping soil, farmers switched back to rice cultivation. However, the process of diversifying or converting from litchi into other crops faced various obstacles and remained at a slow pace. A vast number of farming households stopped growing litchi and searched for non-farm jobs outside the villages. In general, there has been recent declining trend observed in the litchi cultivation of the Thanh Ha district.

The evolution and sustainability of agrarian systems for the prospect of accelerating industrialization

Based on observations during the field surveys of the industrial sites in the Hai Duong province, we have found that there is a strong relationship between the level of industrialization and the increasing intensity and specialization of agrarian systems. Systems which have gradually evolved into specialized intensive systems during the industrialization period as the development of industry greatly encourages the increasing intensity of agrarian systems.

The sustainable development of agricultural systems during the industrialization period is achievable if several potential problems of industry are managed and solved in fundamental ways. Because of the possible transformation of agricultural land into industrial parks, it is foreseeable that such land will go through a reductive. If no land use master plan implemented at the regional level, the food security of the nation will be at risk. The provincial government needs to formulate a long-term land use plan in which specific agricultural land areas, especially the paddy farms, are kept stable during the industrialization era. However, it will be difficult for policymakers to launch a master plan regarding land use if agricultural land is highly fragmented. Hence, land consolidation is necessary in order to set up an appropriate long-term land use plan. Land consolidation not only enables policymakers to devote a given land area to agricultural production, but it also makes it possible to use infertile or unfavorable land areas to improve irrigation and drainage systems and to install industrial zones. Moreover, environmental health is important to consider and protect through good waste management and treatment by manufacturing companies. In this regard, the waste management and treatment practices of all industrial factories need to be well controlled and regularly inspected in accordance with strict environmental regulations that are approved by the government.

Balanced industrial development among the regions of Vietnam is also of great importance in order to encourage the improvement and sustainability of agriculture and rural society. This is characterized by the equilateral diffusion of industrial zones among regions. It is believed that the development of some small or medium industrial parks in remote locations is an engine of economic growth because of the availability of off-farm job opportunities and the rural infrastructure improvement that industry provides. The development of some light industries, such as agro-food processing parks, handicraft industry, and the like, is able to accommodate a huge number of unemployed individuals in rural areas and foster the growth of agriculture. Agro-food processing plants can also collect a large and stable amount of agricultural products from farms in neighbouring regions. Furthermore, the strong relationship between farming households and agro-food companies when it comes to supplying agricultural commodities will act as a powerful incentive for farmers to develop their farming systems.

\section{Development and sustainability of agrarian systems in the context of urbanization}

Along with the prospect of a highly urbanized province, the agrarian systems in Hai Duong would evolve into an urban and peri-urban agricultural system, like in the case of Hanoi and other cities in Vietnam. According to the findings of this study, the characteristics of urban and peri-urban agricultural systems vary between the agro-ecological zones of the province. In general, the concentrated areas of agricultural production will formulate around towns and cities, whereas the small-scale family farms will develop in the available urban spaces.

Over the last decade, as illustrated in the previous parts of this study, several concentrated agricultural areas have rapidly developed in the different zones of Hai Duong, including areas of livestock-fish production in the upper zone (Cam Giang), the vegetable cultivation area in the middle zone (Gia Loc), and fruit plantation in the lower zone (Thanh Ha). In each zone, the concentration of rice cultivation has also been identified in order to ensure food security. These concentrated agricultural areas have provided an important proportion of food and agricultural products to local markets and other regions of Vietnam. These specialized agricultural areas are often developed in the central locations, close to the towns or cities. Therefore, in the scenario where there is a high level of urbanization, the 
specialized farming systems will be improved in the regions close to the urban centres.

In order to develop a sustainable agricultural production in an urbanized situation, it is important for policymakers to implement both appropriate regional planning and supportive policies for the agricultural sector. The planning for urban land use should also identify the specific areas of agricultural concentration in conjunction with the urban regions. Maintaining the stability of a given agricultural land is necessary in order to ensure the food security and economic growth of the province and the whole country. Therefore, it is important to develop a wide range of small and medium towns or cities in different locations of the province rather than in megacity or metropolitan areas. This, on the one hand, prevents regional migration that can lead to the urban poverty, and, on the other hand, fosters the development of agriculture in remote regions. In addition, maintaining productive farmland needs to be supported by the government by diversifying how they are implemented. Reducing some kinds of taxes, especially land tax, is one of the most important supporting actions to help producers in urban areas when there is a high amount of pressure on land. Improving some agricultural public services such as irrigation system, agricultural extension, as well as pest and disease management is also required in order to support urban agriculture development.

For the agricultural producers in urban areas, sustainable agricultural development can be achieved if they practise the required policies properly. In order to do so, they should improve their knowledge and consciousness of safe and environmentally friendly agricultural production practices when implementing urban agriculture. Farming practices and management need to ensure a healthy ecosystem and environment is maintained through low levels of chemical consumption and by avoiding high amounts of wasted inputs and by-products of recycling. The application of biotechnology and information in agriculture is also very important for producers in order to increase their productivity and yield. To increase the family income, producers should also take the most advantage of developed marketing systems in urban areas by accessing the niche market of high income consumers, such as the home delivery of safe products or by supplying big restaurants with their products. Furthermore, they should diversify their sources of income by developing some non-farm activities or by engaging in urban services such as fruit orchard tourism, and relaxing farm fishing. In Hai Duong and other provinces in North Vietnam, the agricultural land use system is now in crisis and poses problems for the sustainable development of agricultural and rural society. Several emerging issues, including fragmentation of agricultural lands, the imperfection of the land market, the increase in paddy farms, and complications with the agricultural land tenure system in the context of industrialization and urbanization, illustrate that new policy for future agricultural land use is in high demand. In many cases, the logic of keeping agricultural land areas does not mean achieving a high yield from crop production. Rather, land is becoming a kind of capital to many farming households because of the rising price of land during industrialization and urbanization. Therefore, it is very difficult for policy makers to design a suitable policy for agricultural land that creates sustainable development for agricultural production.

\section{CONCLUSIONS}

Over the last two decades, Vietnamese farmers have rapidly adapted to the socio-economic and institutional changes through different adaptation and stabilization mechanisms. First, stabilizing food autonomy by maintaining a certain land area for rice cultivation was often the most important strategy that is utilized by the majority of farming households. Second, diversifying the production systems by employing an integrated animal-crop production system or a diversified vegetable or fruit cropping system was another important resilience strategy used by farmers in order to maximize the efficiency of the household resource utilization and reduce risks from their physical and economic capitals. Third, taking the most advantage of market development and increasing food demand by consumers through increasing the intensity and specialization of the production systems is very important for farm households to increase the efficiency of the resources (land, labour, capital) as well as generate more income. In order to limit the negative impacts of physical and economic environments, most farmers have effectively implemented both the operational and strategic flexibility of their production systems by adjusting the production scale of their animal production or plant varieties.

\section{ACKNOWLEDGEMENT}

The authors wish to thank Ms. Bethany Gardner from the Department of Linguistics, the State University of New York at Binghamton, for her kind help in improving the English of this text.

\section{REFERENCES}

Alexander P, Paustian K, Smith P, Moran D. 2015. The economics of soil C sequestration and agricultural emissions abatement. SOIL 1: 331-339. DOI: $10.5194 /$ soil-1-331-2015.

Amuti T, Luo G. 2014. Analysis of land cover change and its driving forces in a desert oasis landscape of Xinjiang, northwest China. Solid Earth 5: 1071-1085. DOI: 10.5194/se-5-1071-2014.

Araya A, Stroosnijder L, Habtu S, Keesstra SD, Berhe M, Hadgu KM. 2012. Risk assessment by sowing date for barley (Hordeum vulgare) in northern Ethiopia. Agricultural and Forest Meteorology 154: 30-37.

Barati AA, Asadi A, Kalantari K, Azadi H, Witlox F. 2015. Agricultural land conversion in Northwest Iran. International Journal of Environmental Research 9: 281-290. DOI: 10.1007/s12061-015-9160-4.

Beniston JW, Lal R, Mercer KL. 2016. Assessing and managing soil quality for urban agriculture in a degraded vacant lot soil. Land Degradation and Development 27: 996-1006. DOI: 10.1002/ldr.2342.

Brevik EC, Cerdà A, Mataix-Solera J, Pereg L, Quinton JN, Six J, Van Oost K. 2015. The interdisciplinary nature of SOIL. SOIL 1: 117-129. DOI: 10.5194/soil-1-117-2015, 2015.

Campos AC, Etchevers JB, Oleschko KL, Hidalgo CM. 2014. Soil microbial biomass and nitrogen mineralization rates along an altitudinal 
gradient on the cofre de perote volcano (Mexico): the importance of landscape position and land use. Land Degradation and Development 25 : 581-593. DOI: 10.1002/ldr.2185.

Costa JL, Aparicio V, Cerdà A. 2015. Soil physical quality changes under different management systems after 10 years in the Argentine humid pampa. Solid Earth 6: 361-371. DOI: 10.5194/se-6-361-2015.

Duglas JMJ, Dillon L. 1997. Farm management for Asia: a systems approach. FAO: Rome, Italy. Rome, Italy; 1-355.

Easdale MH. 2016. Zero net livelihood degradation-the quest for a multidimensional protocol to combat desertification. SOIL 2: 129-134. DOI: 10.5194/soil-2-129-2016.

FAO. 1999. Guidelines for agrarian system diagnosis. Rome, Italy. 1-70.

Galati A, Crescimanno M, Gristina L, Keesstra S, Novara A. 2016. Actual provision as an alternative criterion to improve the efficiency of payments for ecosystem services for $\mathrm{C}$ sequestration in semiarid vineyards. Agricultural Systems 144: 58-64. DOI: 10.1016/j.agsy.2016.02.004.

General Statistics Office. 2012. Results of the 2011 rural, agriculture and fishery census. Statistical Publishing House: Hanoi. Hanoi; 1-388.

Hack-ten Broeke MJD, Kroes JG, Bartholomeus RP, van Dam JC, de Wit AJW, Supit I, Walvoort DJJ, van Bakel PJT, Ruijtenberg R. 2016. Quantification of the impact of hydrology on agricultural production as a result of too dry, too wet or too saline conditions. SOIL 2: 391-402. DOI: $10.5194 /$ soil-2-391-2016.

Hedo J, Lucas-Borja ME, Wic C, Andrés-Abellán M, De Las Heras J. 2015. Soil microbiological properties and enzymatic activities of long-term post-fire recovery in dry and semiarid Aleppo pine (Pinus halepensis M.) forest stands. Solid Earth 6: 243-252. DOI: 10.5194/se-6-243-2015.

Hoeks C, Azadi H, Rafiaani Khachak P, Troyo-Dieguez E, Van Passel S, Witlox F. 2014. Reforming land tenure systems in South Africa: routes to socio-economic and agricultural sustainability. Development Policy Review 32: 647-674. DOI: 10.1111/dpr.12083.

van Ittersum MK, Ewert F, Heckelei T, Wery J, Olsson JA, Andersen E, Bezlepkina I, Brouwer F, Donatelli M, Flichman G, Olsson L, Rizzoli AE, van der Wal T, Wien KE, Wolf J. 2008. Integrated assessment of agricultural systems - a component-based framework for the European Union (SEAMLESS). Agricultural Systems 96: 150-165. DOI: 10.1016/j.agsy.2007.07.009.

Jlassi W, Nadal-Romero E, García-Ruiz JM. 2016. Modernization of new irrigated lands in a scenario of increasing water scarcity: from large reservoirs to small ponds. Cuadernos De Investigacion Geografica 42: 233-259. DOI: 10.18172/cig.2918.

Keesstra S, Pereira P, Novara A, Brevik EC, Azorin-Molina C, ParrasAlcántara L, Jordán A, Cerdà A. 2016a. Effects of soil management techniques on soil water erosion in apricot orchards. Science of the Total Environment 551-552: 357-366. DOI: 10.1016/j.scitotenv.2016.01.182.

Keesstra S, Bouma J, Wallinga J, Tittonell P, Smith P, Cerdà A, Montanarella L, Quinton JN, Pachepsky Y, van der Putten WH, Bardgett RD, Moolenaar S, Mol G, Jansen B, Fresco LO. 2016b. The significance of soils and soil science towards realization of the United Nations Sustainable Development Goals. SOIL 2: 111-128. DOI: 10.5194/soil2-111-2016.

Keith MM. 1995. The conceptual basic for targeting farming systems: domains, zones and typologies. Journal for Farming Systems Research -Extension 5: 19-37.

Lasanta T, Nadal-Romero E, Errea P, Arnáez J. 2016. The effect of landscape conservation measures in changing landscape patterns: a case study in Mediterranean mountains. Land Degradation and Development 27: 373-386. DOI: 10.1002/ldr.2359.

Lu X, Yan Y, Sun J, Zhang X, Chen Y, Wang X, Cheng G. 2015. Short-term grazing exclusion has no impact on soil properties and nutrients of degraded alpine grassland in Tibet, China. Solid Earth 6: 1195-1205. DOI: 10.5194/se-6-1195-2015.

Luu L. 2001. The VAC System in Northern Viet Nam. Integrated 115 Agriculture-Aquaculture: A Primer. Rome, Italy, FAO.

Mazoyer M, Roudart L. 2006. A history of world agriculture-from the Neolithic age to the current crisis. Earthscan: London, UK. London, UK.

McIntyre BD, Herren HR, Wakhungu J, Watson RT. 2009. Agriculture at a crossroads-global report. International Assessment of Agricultural
Knowledge, Science and Technology for Development Washington, USA, Island Press. 1-590.

Meadows DH. 2009. Thinking in system-a primer. Earthscan: London, UK. London, UK; 1-218.

Mekonnen M, Keesstra SD, Baartman JE, Ritsema CJ, Melesse AM. 2015. Evaluating sediment storage dams: structural off-site sediment trapping measures in northwest Ethiopia. Cuadernos De Investigacion Geografica 41: 7-22. DOI: $10.18172 /$ cig.2643.

de Mûelenaere S, Frankl A, Haile M, Poesen J, Deckers J, Munro N, Veraverbeke S, Nyssen J. 2014. Historical landscape photographs for calibration of Landsat land use/cover in the Northern Ethiopian highlands. Land Degradation and Development 25: 319-335. DOI: 10.1002/ ldr.2142.

Muller D, Zeller M. 2002. Land use dynamics in the central highlands of Vietnam: a spatial model combining village survey data with satellite imagery interpretation. Agricultural Economics 27: 333-354. DOI: 10.1111/j.1574-0862.2002.tb00124.x.

Nicholson C, Heleba D. 2000. Under the blade: the conversion of agricultural landscapes. Agricultural Systems 63: 141-143.

Novara A, Gristina L, Guaitoli F, Santoro A, Cerdà A. 2013. Managing soil nitrate with cover crops and buffer strips in Sicilian vineyards. Solid Earth 4: 255-262. DOI: 10.5194/se-4-255-2013.

Novara A, Rühl J, La Mantia T, Gristina L, La Bella S, Tuttolomondo T. 2015. Litter contribution to soil organic carbon in the processes of agriculture abandon. Solid Earth 6: 425-432. DOI: 10.5194/se-6-4252015.

Novara A, Keesstra S, Cerdà A, Pereira P, Gristina L. 2016. Understanding the role of soil erosion on co2-c loss using 13c isotopic signatures in abandoned Mediterranean agricultural land. Science of the Total Environment 550: 330-336. DOI: 10.1016/j.scitotenv.2016.01.095, 2016.

Rasmussen LV, Rasmussen K, Reenberg A, Proud S. 2012. A system dynamics approach to land use changes in agro-pastoral systems on the desert margins of Sahel. Agricultural Systems 107: 56-64. DOI: 10.1016/j.agsy.2011.12.002.

Rodrigo-Comino J, Seeger M, Senciales JM, Ruiz-Sinoga JD, Ries JB. 2016. Spatial and temporal variation of soil hydrological processes on steep slope vineyards (Ruwel-Mosel Valley, Germany). Cuadernos De Investigacion Geografica 42: 281-306. DOI: 10.18172/cig.2934.

Rudi LM, Azadi H, Witlox F, Lebailly P. 2014. Land rights as an engine of growth? An analysis of Cambodian land grabs in the context of development theory. Land Use Policy 38: 564-572. DOI: 10.1016/j. landusepol.2013.12.016.

Smith P, Cotrufo MF, Rumpel C, Paustian K, Kuikman PJ, Elliott JA, McDowell R, Griffiths RI, Asakawa S, Bustamante M, House JI, Sobocká J, Harper R, Pan G, West PC, Gerber JS, Clark JM, Adhya T, Scholes RJ, Scholes MC. 2015. Biogeochemical cycles and biodiversity as key drivers of ecosystem services provided by soils. SOIL 1: 665-685. DOI: 10.5194/soil-1-665-2015.

Torres L, Abraham EM, Rubio C, Barbero-Sierra C, Ruiz-Pérez M. 2015. Desertification research in Argentina. Land Degradation and Development 26: 433-440. DOI: 10.1002/ldr.2392.

Vieira RMSP, Tomasella J, Alvalá RCS, Sestini MF, Affonso AG, Rodriguez DA, Barbosa AA, Cunha APMA, Valles GF, Crepani E, De Oliveira SBP, De Souza MSB, Calil PM, De Carvalho MA, Valeriano DM, Campello FCB, Santana MO. 2015. Identifying areas susceptible to desertification in the Brazilian northeast. Solid Earth 6: 347-360. DOI: $10.5194 / \mathrm{se}-6-347-2015$.

Xie LW, Zhong J, Chen FF, Cao FX, Li JJ, Wu LC. 2015. Evaluation of soil fertility in the succession of karst rocky desertification using principal component analysis. Solid Earth 6: 515-524. DOI: 10.5194/se-6-515-2015.

Yu Q, Wu W, Verburg PH, Vliet JV, Yang P, Zhou Q, Tang H. 2013. A survey-based exploration of land-system dynamics in an agricultural region of Northeast China. Agricultural Systems 121: 106-116. DOI: 10.1016/j.agsy.2013.06.006.

Zhang K, Zheng H, Chen FL, Ouyang ZY, Wang Y, Wu YF, Lan J, Fu M, Xiang XW. 2015. Changes in soil quality after converting Pinus to Eucalyptus plantations in southern China. Solid Earth 6: 115-123. DOI: $10.5194 / \mathrm{se}-6-115-2015$. 